ISSN 1981-416X

\title{
Interações on-line nas atividades de orientação de trabalhos finais de curso: um estudo sobre as práticas dos orientadores no Brasil e Portugal
}

Online interactions in the orientation activities of final works: a study of the advisors in Brazil and Portugal

Interacciones en línea en el trabajo final del curso: un estudio sobre las prácticas de los orientadores en Brasil y Portugal

\section{Paulo Roberto Prado Constantino ${ }^{[a]}$, Susana Henriques ${ }^{[b]^{*}}$}

\author{
[a] Universidade Estadual de São Paulo (UNESP), Marília, SP, Brasil \\ [b] Universidade Aberta de Portugal, Lisboa, Portugal
}

\section{Resumo}

Este artigo é parte de uma investigação mais ampla sobre os fundamentos e práticas de orientação dos trabalhos finais de cursos em modalidades on-line [dissertações, teses, monografias, projetos experimentais], com foco sobre instituições educacionais superiores em Portugal e no Brasil. No presente, a reflexão assenta-se sobre as interações on-line 
desenvolvidas durante estas orientações. A partir da análise de conteúdo em entrevistas com oito professores, pretendeu-se um mapeamento das preferências e práticas de interações, analisando aspectos que envolvem os canais comunicacionais e seus recursos e tipos; os tempos e modos para interações síncronas e assíncronas e a sua periodicidade; a formação de redes sociais e comunidades de aprendizagem; e os substratos das relações entre os indivíduos e da criação de redes comunicacionais com finalidades de aprendizagem. Os resultados apontam algumas diretivas para a educação on-line, como contributos da pesquisa.

Palavras-chave: Interações on-line. Orientação de trabalhos finais. Formação de professores.

\section{Abstract}

This article is part of a wider research of the foundations and practices of orientation of the final works in online modalities [dissertations, theses, monographs, projects], focusing on higher educational institutions in Portugal and Brazil. At present, the reflection is based on the online interactions developed during these works, verifying the possibilities between advisors and students, between advisors and of these and the supervision of the courses. From the analysis of content in interviews with eight guiding teachers, it was intended a mapping of preferences and practices of interactions, analyzing aspects that involve the communication channels and their resources and types; times and modes for synchronous and asynchronous interactions and their periodicity; the formation of social networks and learning communities; and the substrates of the relationships and the creation of communication networks for learning purposes. The results point out some guidelines for online education as research contributions.

Keywords: Online interactions. Final works orientation. Teacher development.

\section{Resumen}

Este artículo participa en una investigación más amplia sobre los fundamentos y prácticas de orientación em línea de los trabajos finales [disertaciones, tesis, monografías, proyectos 
experimentales], centrándose en las instituciones de educación superior en Portugal y Brasil. En el presente, la reflexión se asienta sobre las interacciones desarrolladas durante estas orientaciones, mirando las posibilidades entre orientador y cursistas, entre orientadores y entre éstos y la supervisión o coordinación de los cursos. A partir del análisis de contenido en entrevistas con ocho profesores, se pretendió un mapeamiento de las preferencias y prácticas de interacciones, analizando aspectos que involucra los canales comunicacionales y sus recursos y tipos; los tiempos y modos para interacciones síncronas y asíncronas y su periodicidad; la formación de redes sociales y comunidades de aprendizaje; y los sustratos de las relaciones entre los individuos y de la creación de redes comunicacionales con finalidades de aprendizaje. Los resultados apuntan algunas directivas para la educación online, como aportaciones de la investigación.

Palabras-clave: Interacciones en línea. Orientación de trabajos finales. Formación de profesores.

\section{Introdução}

O presente artigo faz parte de uma investigação mais ampla sobre os fundamentos e práticas de orientação dos trabalhos finais de cursos em modalidades on-line [dissertações, teses, monografias, projetos experimentais], com foco sobre instituições educacionais superiores em Portugal e no Brasil.

Interações educacionais são reconhecidas como essenciais nas experiências de educação a distância e on-line (CABRAL, 2015) e no trabalho de orientação para a pesquisa científica (MACHADO, 2000).

Sem pretender analisar os fundamentos linguísticos ou comportamentais, nos atemos ao mapeamento e discussão de seus elementos comunicacionais e pedagógicos, a partir do trabalho de diferentes orientadores, verificando as possibilidades suscitadas entre orientador e cursistas e vice-versa, e a supervisão ou coordenação dos cursos em que atuam.

Entre os seis grandes grupos de competências digitais dos educadores apontadas por Redecker (2017) em recente publicação da União 
Europeia, as interações on-line são descritas como parte importante do engajamento profissional dos professores, da criação de pesquisas e resolução de problemas, da aquisição de competências em informação e comunicação, do processo de ensino e da aprendizagem, bem como das diferentes formas de envolvimento dos alunos. Sob esta diretriz, a discussão da orientação de trabalhos finais requererá a apropriação de conhecimentos variados. Neste recorte, avançamos sobre o trabalho colaborativo e as bases sobre as quais são erigidas as interações dos orientadores em campo.

\section{Marco conceitual para a investigação}

A função do professor orientador de trabalhos finais está estabelecida no quadro funcional da educação a distância (ALBUQUERQUE et al., 2015). No entanto, a literatura específica que menciona as interações entre cursistas e orientadores apresentou-se escassa (ALBUQUERQUE et al., 2015; CHASSOT, 2006; FERRETTI, 1997; MARQUES, 2006; SAVIANI, 2006) durante a revisão empreendida.

À parca literatura, associa-se o problema da formação do professor orientador, diagnosticado há quase duas décadas por Ana Maria Netto Machado (2000) e sobre o qual pouco se avançou:

O que nos autoriza a acreditar que o simples fato de pesquisarmos nos capacita para orientar? Assim como ensinar é diferente de pesquisar, e ninguém questionaria a necessidade de uma formação específica para fazer de um professor um pesquisador, por quê razão a orientação seria uma atividade espontânea e natural? Nada parece mais lógico do que esperar que uma formação específica deva entrar em cena, também na transformação de um pesquisador em orientador. [...] Mas o fato é que, de modo geral, temos encarado a função do orientador como se fosse uma atividade simples, praticamente inerente ao pesquisador, a qual ele deveria desde sempre dominar. (MACHADO, 2000, p. 142). 
Reconhecer a proeminência de uma formação para orientadores em cursos on-line foi um marco inicial de nossa proposta. Estabelecer as diferentes dimensões desta tarefa, como as que envolvem habilidades e conhecimentos de pesquisa, domínio da área de atuação em que as pesquisas se posicionam, aspectos de redação, comunicação e interação, domínio das tecnologias; foi o momento seguinte da investigação.

Partindo de uma abordagem das interações educacionais on-line, em um artigo fundante da temática, Moore (1989) reconhecia três formas básicas: estudante-conteúdo, estudante-estudante e estudante-professor. Dentre as três, avançamos especialmente sobre a interação entre professor [orientador] e os alunos, descrita por Cabral (2015) nos seguintes termos:

A interação Estudante-Professor pode assumir a forma de instrução direta através de lições e palestras ou através de diálogo, feedbacks, e incentivos ao estudante. Além disso, os estudantes podem interagir com o professor, fazendo perguntas, apresentando trabalhos ou discutindo problemas com o professor. A interação Estudante-Professor é o que permite o feedback entre o educador e o estudante. O estudante é capaz de aprender com a experiência e com o conhecimento do professor e o professor é capaz de aferir e avaliar as necessidades dos estudantes. Moore refere a necessidade de um professor para ajudar os estudantes a aplicar os novos conhecimentos corretamente e a aplicá-los o mais intensamente e amplamente possível ou desejável e tornar conscientes as áreas de aplicação desses novos conhecimentos (CABRAL, 2015, p. 32).

Ainda que se admita nas interações educacionais um certo grau de variabilidade, dependendo dos tipos de produtos, ciclos de estudo ou dos professores e cursistas envolvidos (PEREIRA et al., 2007), estas deveriam, de acordo com os últimos autores, ultrapassar os feedbacks de presença virtual ou da avaliação de atividades e checkpoints nos ambientes de aprendizagem, em direção ao amplo engajamento nas atividades educacionais. 
Os desafios de uma interação de qualidade entre professores, tutores e cursistas também foram assinalados por outros pesquisadores da educação online, como Mill et al., 2008 e Sousa \& Dias, 2017. Em nosso caso, não apenas esta perspectiva de interação entre orientador e cursista poderia ser considerada: a possibilidade de reforçar as interações entre os cursistas nas formações online e mistas vem sendo prestigiada nos documentos diretivos e matrizes curriculares de cursos EaD (ALMEIDA, 2014), ainda que pesquisas específicas se refiram às interações entre estudantes apenas como "moderadas" (DIAS et al., 2016) em seus resultados. Observa-se, nesta trilha, uma possibilidade de aperfeiçoamento.

Ao avançar sobre as interações on-line, o Modelo Pedagógico Virtual da Universidade Aberta de Portugal (PEREIRA et al., 2007), oriundo de uma das instituições pesquisadas, traz em suas guidelines o primado destas interações nas práticas educacionais:

A interacção assume-se como um processo subjacente ao processo de ensino e de aprendizagem no contexto deste modelo. Se nas primeiras gerações de ensino a distância, a interacção era fundamentalmente entendida como interacção estudante-conteúdo e interacção estudante-professor, no modelo aqui explicitado ela alarga-se de forma decisiva à interacção estudante-estudante, através da criação de grupos de discussão no interior de cada turma virtual, implicando o seu planeamento prévio [o desenho instrucional] e estratégias de activação da aprendizagem, de modo a estimular a iniciativa e o envolvimento dos estudantes, bem como a garantir seu empenhamento e orientar a natureza do seu trabalho (PEREIRA et al., 2007, p. 13).

O aprofundamento destas interações entre cursistas seria, na perspectiva de Pereira et al. (2007), o próximo passo que o ensino a distância poderia ter empreendido nas últimas duas décadas, mas que ainda encontraria resistências, especialmente no contexto das orientações de trabalhos finais, marcadas por relações notadamente bidirecionais [orientador-cursista]. No momento atual, a relação entre o aluno e seu orientador, sob o aspecto qualitativo, nos parece mais adequadamente descrita 
pelo modelo "eu-tu", localizado por Primo (2007) em suas investigações sobre interações on-line e que ofereceria um contato recursivo e íntimo entre os atores:

[...] A historicidade dessa interação tem impacto sobre os interagentes e o próprio relacionamento entre eles. Em outras palavras, a interação entre eu e tu não é atomizada. Mais do que um acúmulo de ações sequenciais ou uma troca "bancária" (de tipo "toma-lá-dá-cá"), os interagentes constroem entre si um relacionamento. As ações manifestas e a interpretação dos comportamentos (do outro e de seus próprios) se desenvolvem também em virtude da relação "inventada" em conjunto durante o percurso da interação, mesmo que haja grandes lapsos temporais entre cada encontro. Cada novo intercâmbio atualiza esse relacionamento, que exercerá novos condicionamentos nos atos futuros. Trata-se, pois, de um processo recursivo. Contudo, não se pode apagar atos anteriores, como se deleta um arquivo que deixa de interessar. Outrossim, atos subsequentes podem motivar ressignificações de interações anteriores (PRIMO, 2007, p. 08).

Consideramos que o caráter recursivo - e responsivo - das interações on-line seja também estendido às atividades de orientação de trabalhos finais. Perscrutando estes elementos das interações educacionais de natureza colaborativa nas práticas de um grupo de orientadores que estivessem atuando no Brasil e em Portugal, avançou-se para a pesquisa de campo. Esta, promoveu entrevistas com oito destes professores, sobre as quais se pretendia um mapeamento das preferências e práticas de interações educacionais, analisando aspectos que envolviam os canais comunicacionais e seus recursos e tipos, além dos tempos e modos para interações síncronas e assíncronas e a sua periodicidade. Também, houve um mapeamento sobre a formação de redes sociais e comunidades de aprendizagem, e os substratos das relações entre os indivíduos e da criação de redes comunicacionais com finalidades de aprendizagem. 


\section{Caracterização da pesquisa e dos participantes}

A pesquisa de caráter exploratório quanto aos objetivos (GIL, 2002), foi desenvolvida durante os anos de 2017 e 2018 entre professores orientadores de trabalhos finais em ofertas formativas on-line em Portugal e no Brasil, atuantes em instituições como a Universidade Aberta [Portugal], Universidade Estadual Paulista - Unesp e o Centro Paula Souza [Brasil]. A seleção destes sujeitos baseou-se em critérios de conveniência e de sua atuação na área educacional, e as entrevistas foram feitas presencialmente e por videoconferência. Obtidos os dados, empregou-se uma abordagem descritiva, baseada na análise de conteúdo (BARDIN, 1977), que consistia na compilação dos dados e na construção de categorias de análise para o conjunto de respostas dos professores formadores.

Inicialmente, para abordá-los, foi elaborado um roteiro de entrevista não diretiva, que incluiu dimensões como a caracterização do trabalho de orientação quanto ao tempo de experiência, número de trabalhos orientados e produtos resultantes, aprofundando-se em seguida nos aspectos específicos das interações:

Quadro 1 - Síntese das dimensões abordadas nas entrevistas com orientadores

\begin{tabular}{|c|c|}
\hline Dimensões & Indicadores/Descritores \\
\hline $\begin{array}{l}\text { Caracterização do } \\
\text { trabalho pessoal do } \\
\text { orientador }\end{array}$ & $\begin{array}{l}\text { - Tempo de atuação na EaD } \\
\text { - Número de trabalhos orientados em cursos EaD }\end{array}$ \\
\hline $\begin{array}{l}\text { Caracterização } \\
\text { da orientação de } \\
\text { trabalhos finais/TCC }\end{array}$ & $\begin{array}{l}\text { - Modalidades em que são implementadas } \\
\text { - Tipos de produtos finais [artigos, projetos, monografias, dissertações, teses] } \\
\text { - Duração dos cursos e dos processos de orientação }\end{array}$ \\
\hline $\begin{array}{l}\text { Práticas gerais de } \\
\text { orientação }\end{array}$ & $\begin{array}{l}\text { - Diagnóstico do perfil e das necessidades educacionais dos cursistas } \\
\text { a distância; } \\
\text { - Controle dos processos: planejamento da pesquisa, prazos, acessos; } \\
\text { - Como se estabelecem os primeiros contatos com os orientandos; } \\
\text { - Metodologia científica / ferramentas para o desenvolvimento das } \\
\text { pesquisas / projetos; } \\
\text { - Recursos disponibilizados para a redação / concepção dos produtos finais; } \\
\text { - Procedimentos de editoração/correção/avaliação dos produtos parciais } \\
\text { e/ou finais. }\end{array}$ \\
\hline
\end{tabular}


(conclusão)

\begin{tabular}{|l|l|}
\hline \multicolumn{1}{|c|}{ Dimensões } & \multicolumn{1}{c|}{ Indicadores/Descritores } \\
\hline & - Modelos de interações; \\
& - entre os cursistas \\
& - entre orientador e cursistas \\
& - entre orientador e supervisão educacional ou coordenação dos cursos \\
& - entre orientadores \\
& - canais e tipos de comunicação estabelecidos; \\
& - periodicidade. \\
\hline & - Formação em / para orientação de trabalhos finais \\
& - Formatos [presencial, online]; \\
Formação docente & - Duração; \\
dos orientadores & - Referenciais teóricos para a orientação; \\
& - Referências pessoais [informais, exemplos na trajetória profissional e \\
& estudantil] sobre o trabalho de orientação. \\
\hline
\end{tabular}

Todos os entrevistados atuavam em cursos semipresenciais ou exclusivamente on-line. Sobre o contexto geral destes sujeitos, foi possível descrever seu país de atuação, gênero, a titulação destes professores, os anos de trabalho em cursos da modalidade $\mathrm{EaD}$, o número e o tipo de produtos resultantes desta atividade de orientação:

Quadro 2 - Caracterização dos participantes das entrevistas, sua atuação e produção em cursos EaD

\begin{tabular}{|c|l|l|l|c|c|l|}
\hline Orientador & Gênero & $\begin{array}{c}\text { País de } \\
\text { atuação } \\
\text { (principal) }\end{array}$ & $\begin{array}{c}\text { Titulação do } \\
\text { orientador }\end{array}$ & $\begin{array}{c}\text { Anos de atuação } \\
\text { na orientação } \\
\text { em modalidades } \\
\text { de EaD }\end{array}$ & $\begin{array}{l}\text { Número de } \\
\text { trabalhos } \\
\text { orientados } \\
\text { em EaD }\end{array}$ & $\begin{array}{l}\text { Tipos de produções } \\
\text { geradas nas } \\
\text { orientações em } \\
\text { modalidades EaD }\end{array}$ \\
\hline E1 & Masculino & Portugal & Doutor & 8 & 32 & $\begin{array}{l}\text { Monografias, } \\
\text { dissertações, teses }\end{array}$ \\
\hline E2 & Feminino & Portugal & Doutor & 16 & 30 & $\begin{array}{l}\text { Monografias, } \\
\text { dissertações, teses }\end{array}$ \\
\hline E3 & Feminino & Portugal & Doutor & 8 & 11 & $\begin{array}{l}\text { Monografias, } \\
\text { dissertações, teses }\end{array}$ \\
\hline E4 & Feminino & Portugal & Doutor & 10 & 33 & $\begin{array}{l}\text { Monografias, } \\
\text { dissertações, teses }\end{array}$ \\
\hline E5 & Feminino & Brasil & Doutor & 11 & 77 & Monografias \\
\hline E6 & Feminino & Brasil & Mestre & 5 & 27 & Monografias, Artigos \\
\hline E7 & Feminino & Brasil & Doutor & 5 & 81 & Artigos \\
\hline E8 & Feminino & Brasil & Doutor & 11 & 96 & $\begin{array}{l}\text { Monografias, } \\
\text { dissertações }\end{array}$ \\
\hline
\end{tabular}


A experiência dos orientadores portugueses incluía a orientação de dissertações e teses em cursos semipresenciais ou exclusivamente a distância, que não estavam contemplados nas atividades dos orientadores brasileiros. Daí também advém a disparidade entre o número de orientações entre os professores portugueses e brasileiros, realçada pelo escopo e a extensão dos produtos resultantes - dissertações e teses certamente são mais extensas, o que explicaria o número mais baixo de ocorrências de produtos entre os primeiros. Em comum, todos possuíam experiências em orientações de trabalhos em cursos presenciais, antes de trabalharem em cursos on-line, não computadas no Quadro 2.

Postas estas informações e a caracterização inicial da pesquisa e dos participantes envolvidos, apresentaremos um recorte destes resultados obtidos quanto às interações educacionais on-line.

\section{Resultados obtidos}

A discussão das práticas específicas dos orientadores de supervisão on-line ou da formação docente para a atividade será abordada oportunamente em outras publicações. Neste recorte da pesquisa, classificamos os resultados que estivessem diretamente relacionados às interações educacionais, como no extrato de exemplos que demonstramos a seguir: 


\section{Quadro 3 - Dimensões das interações presentes nos trabalhos dos orientadores entrevistados} (continua)

\begin{tabular}{|c|c|c|}
\hline $\begin{array}{l}\text { Indicadores/ } \\
\text { Descritores }\end{array}$ & Alguns exemplos verificados & \% de ocorrências \\
\hline $\begin{array}{l}\text { Interações } \\
\text { entre } \\
\text { cursistas }\end{array}$ & $\begin{array}{l}\text { [E1]: Após o primeiro momento de interação em fóruns entre os } \\
\text { cursistas, a interação fica mais intensa com o orientador, pela própria } \\
\text { natureza do trabalho. } \\
\text { [E2]: Eu posso estar em contato, quando eu acho que é interessante eu } \\
\text { tento, mas não é algo que seja muito fácil, esse trabalho on-line de ajuntar, } \\
\text { você consegue trabalhar de forma colaborativa num momento sim, mas } \\
\text { juntar os estudantes é um pouco mais complicado do que no presencial. } \\
\text { [E3]: Eles preferem mais a interação individual comigo, eu acho que a } \\
\text { participação nos fóruns coletivos fica mais para as notícias. Onde eu tenho } \\
\text { resultados muito mais interessantes é no Skype, porque eles dão conselhos } \\
\text { uns aos outros no Skype em grupo e eu já percebi que em alguns casos, } \\
\text { mesmo sem eu estar presente, eles fazem entre eles isso, já aconteceu. } \\
\text { [E6]: O fórum é muito importante nesse sentido, existem muitas } \\
\text { pessoas que não são favoráveis à utilização do fórum, mas eu vejo } \\
\text { nele um caminho à interatividade, porque senão o aluno de EaD fica } \\
\text { extremamente isolado. } \\
\text { [E8]: Eles interagem entre eles nos fóruns, mas pouco. }\end{array}$ & $\begin{array}{l}75 \% \text { dos orientadores } \\
\text { apontaram a baixa } \\
\text { interação entre os } \\
\text { cursistas/ } \\
\text { orientandos }\end{array}$ \\
\hline $\begin{array}{l}\text { Interações } \\
\text { orientadores- } \\
\text { cursistas }\end{array}$ & $\begin{array}{l}\text { [E2]: Isso também é uma parte do processo de orientação que eu organizo } \\
\text { com eles, além disso, eu também tenho um espaço no Facebook. Eu uso } \\
\text { o Facebook como trabalho, tenho espaço que são as orientações. Tem } \\
\text { as orientações, feitas a forma de comunicação até o espaço no Moodle e } \\
\text { também tem espaço nas redes. } \\
\text { [E4]: Há momentos que é importante nos falarmos, então marcamos } \\
\text { reuniões no Skype e vou dizer quais são os momentos: na escolha das } \\
\text { metodologias [...] e na revisão final. } \\
\text { [E5]: Eles quiseram fazer orientação presencial, ou então a gente pode } \\
\text { conversar por Skype, mas eles queriam vir aqui para nós conversarmos } \\
\text { pessoalmente, então nós também conseguimos fazer essa aproximação. } \\
\text { Eu acho que eu deixo isso livre para o aluno. Se ele quiser vir, nós } \\
\text { marcamos um horário. No on-line, (o feedback é) imediato. Dou retorno } \\
\text { no máximo } 24 \text { horas dentro do sistema, mas para dar um feedback de } \\
\text { correção eu não consigo dar em } 24 \text { horas. } \\
\text { [E8] Eu procuro trabalhar no Skype, mas com pequenos grupos, } \\
\text { entendeu, não com todos. [...] Vou agrupando por meio dos temas que } \\
\text { eles trazem [...] Tudo isso feito ocasionalmente por Skype, reuniões em } \\
\text { pequenos grupos. } \\
\text { [E3]: Tenho como prática realizar uma reunião por mês em grupo, na } \\
\text { verdade são duas, porque eu tenho dois grupos constituídos e também vai } \\
\text { de acordo com o tempo da pessoa, por Skype. } \\
\text { Na plataforma Moodle eu tenho um espaço, como se fosse uma unidade } \\
\text { curricular, que se chama espaço da orientação, onde eu inscrevo todos os } \\
\text { meus orientandos, seja do mestrado ou do doutoramento, estão todos } \\
\text { juntos para que eles tenham também uma possibilidade de criar ali um } \\
\text { intercâmbio entre eles [...] tem que haver uma interação por escrito entre } \\
\text { nós de capítulos, textos. }\end{array}$ & $\begin{array}{l}75 \% \text { dos orientadores } \\
\text { privilegiam } \\
\text { momentos de } \\
\text { interação on-line } \\
\text { síncrona, alternados } \\
\text { com o exame da } \\
\text { produção escrita em } \\
\text { fóruns e trechos dos } \\
\text { produtos finais } \\
\text { 37,5\% estabelecem } \\
\text { momentos de } \\
\text { interações on-line } \\
\text { síncronas com grupos } \\
\text { de alunos } \\
\text { 50\% estabelecem } \\
\text { critérios e a } \\
\text { periodicidade das } \\
\text { interações junto aos } \\
\text { seus orientandos } \\
\text { 50\% mencionaram } \\
\text { a agilidade dos } \\
\text { processos de } \\
\text { feedback e correções } \\
\text { nos produtos } \\
\text { finais, em relação } \\
\text { às orientações } \\
\text { presenciais mais } \\
\text { tradicionais }\end{array}$ \\
\hline
\end{tabular}


(continuação)

\begin{tabular}{|c|c|c|}
\hline \multirow[t]{2}{*}{$\begin{array}{l}\text { Indicadores/ } \\
\text { Descritores }\end{array}$} & Alguns exemplos verificados & \% de ocorrências \\
\hline & $\begin{array}{l}\text { [E2] Recai muito mais a responsabilidade da produção do trabalho em } \\
\text { cima dele [cursista] e ele não divide muito com você [...] Há exigência } \\
\text { da produção, eu acho que essa é a grande diferença, a exigência de se } \\
\text { tornar responsável muito mais do que ter presencialidade. Isso é uma } \\
\text { coisa que se observa, outra coisa é qualidade do material e de } \\
\text { sua interação. } \\
\text { [E7]: Mensagens aos cursistas eu procuro sempre usar o ambiente virtual } \\
\text { de aprendizagem. Eu uso e-mail pouquíssimo. Porque eu sigo bastante o } \\
\text { ambiente, eu prefiro, porque fica tudo registrado. E-mail em último caso, } \\
\text { somente quando o aluno não acessa o curso. } \\
\text { [E8]: Meu primeiro contato com eles sempre se deu por meio do } \\
\text { Moodle, abrimos uma página específica, você tem o fórum... }\end{array}$ & \\
\hline $\begin{array}{l}\text { Interações } \\
\text { entre } \\
\text { orientadores } \\
\text { e a } \\
\text { supervisão } \\
\text { educacional } \\
\text { ou } \\
\text { coordenação } \\
\text { dos cursos }\end{array}$ & $\begin{array}{l}\text { [E1]: A coordenação do curso, por estar próxima aos estudantes, } \\
\text { também ajuda a fazer esta ponte entre os colegas orientadores. Não há } \\
\text { supervisão estabelecida, somente a coordenação. } \\
\text { [E2]: Não há supervisão nos cursos de atuação. } \\
\text { [E3]: Eu não oriento todos os meus orientandos da mesma forma, então } \\
\text { não posso exigir que os orientadores do mestrado tenham exatamente } \\
\text { as mesmas práticas para o enquadramento. Nesse sentido, tentamos } \\
\text { encontrar um meio termo entre proporcionar uma monitorização do que } \\
\text { que estava a acontecer. } \\
\text { [E4]: Assim como já fiz Skype com os alunos, faço sempre com os } \\
\text { professores um resumo do que que aconteceu e o que a gente pode } \\
\text { fazer para tentar ajudá-los. } \\
\text { [E6]: Eu acho que [supervisor] tem que alertar muito o orientador. Acho } \\
\text { que é um papel: quando acontecer algo, chamar o orientador e falar } \\
\text { "olha dá uma olhada em tal coisa, tal pessoa", eu acho que são coisas } \\
\text { que a gente precisa nestes cursos. }\end{array}$ & 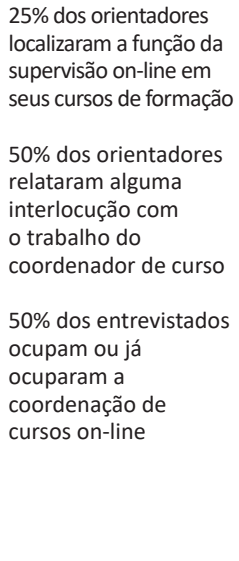 \\
\hline $\begin{array}{l}\text { Interações } \\
\text { entre } \\
\text { orientadores }\end{array}$ & $\begin{array}{l}\text { [E2]: Sim, nos acostumamos conversar entre nós presencialmente. Ao } \\
\text { dividirmos as tarefas ou respeitar essa hierarquia, então o estudante manda } \\
\text { o trabalho, o orientador é o que vê primeiro e depois o coorientador } \\
\text { concorda ou não. [...] Depende do colega e do estilo que é dele. } \\
\text { [E6]: O esforço da gente é para que tenha interação, mas acredito que } \\
\text { isso não aconteça. Inclusive a interação no caso deste curso, que tem } \\
\text { tutor e tem orientador de TCC, essas duas pessoas deveriam trabalhar } \\
\text { extremamente integradas, mas isso não acontece com frequência. } \\
\text { [E7]: Eu busco muito essa interação com os orientadores, mas eu } \\
\text { percebo que não há muita. } \\
\text { [E8]: Eu acho muito importante um fórum dos orientadores, porque } \\
\text { ele possibilita essa interação entre os mais experientes e os menos } \\
\text { experientes. Depois eu conversava com os orientadores por Skype pela } \\
\text { própria plataforma. }\end{array}$ & $\begin{array}{l}25 \% \text { dos orientadores } \\
\text { mencionaram alguma } \\
\text { interação com seus } \\
\text { colegas orientadores } \\
\text { sobre a atuação } \\
\text { nos cursos }\end{array}$ \\
\hline
\end{tabular}


(conclusão)

\begin{tabular}{|c|c|c|}
\hline $\begin{array}{c}\text { Indicadores/ } \\
\text { Descritores }\end{array}$ & Alguns exemplos verificados & \% de ocorrências \\
\hline $\begin{array}{l}\text { Canais e } \\
\text { recursos } \\
\text { empregados }\end{array}$ & $\begin{array}{l}\text { [E1]: Marco uma reunião por Skype ou presencialmente para discutir as } \\
\text { questões específicas das pesquisas. } \\
\text { [E2]: Isso também é uma parte do processo de orientação que eu } \\
\text { organizo com eles, além disso eu também tenho um espaço no Facebook. } \\
\text { Eu uso o Facebook como trabalho, tenho espaço que são as orientações. }\end{array}$ & $\begin{array}{l}75 \% \text { dos } \\
\text { orientadores usam } \\
\text { videoconferências em } \\
\text { suas interações de } \\
\text { orientação } \\
100 \% \text { dos } \\
\text { orientadores em } \\
\text { Portugal usam as } \\
\text { videoconferências } \\
100 \% \text { dos } \\
\text { orientadores no } \\
\text { Brasil não usam } \\
\text { ou usam pouco as } \\
\text { videoconferências } \\
\text { - preferindo as } \\
\text { interações textuais } \\
\text { nos ambientes de } \\
\text { aprendizagem ou } \\
\text { e-mails } \\
25 \% \text { empregam } \\
\text { sistematicamente } \\
\text { redes sociais } \\
\text { no processo de } \\
\text { orientação }\end{array}$ \\
\hline
\end{tabular}

Os trabalhos de orientação entre os professores e os cursistas seguem, em geral, um padrão identificado na literatura especializada: uma combinação de discussões coletivas "com um atendimento individual sistemático, em que o orientador procurava compreender as dificuldades de cada aluno, propiciando os estímulos necessários ao adequado desenvolvimento de sua formação como pesquisador" (SAVIANI, 2006, p. 160), passando também ao "acompanhamento solícito de um leitor qualificado" (MARQUES, 2006, p. 232-233), quanto ao cumprimento de prazos e outros aspectos instrumentais da pesquisa. Este padrão seria "parte fundamental da formação dos cursistas-pesquisadores, que se beneficiariam da experiência de seus orientadores nestas interações" (E1), verificado nas interações da maioria dos entrevistados.

A circulação entre o coletivo e o individual seriam parte constitutiva das orientações on-line. O entrevistado 3 sintetizou esta dinâmica de atuação: 
Há uma dimensão individual e uma dimensão coletiva, há uma dimensão que ocorre por escrito, seja por e-mail ou no fórum. O fórum também é muito usado como um registro das interações dos grupos e às vezes é precioso você ir até lá resgatar os debates, para evitar perdas de processos de trabalho (E3).

Não nos surpreende, portanto, que os fóruns - prática consagrada de interação entre cursistas e também professores na literatura (ALMEIDA, 2014) - seja ampliado às atividades de orientação, sendo mencionado por diferentes professores como uma ferramenta útil para o registro das orientações. Outras possibilidades, como as trocas de arquivos de áudio ou vídeo, poderiam ser incluídas neste ponto, de modo que a informação seja agilizada em multimeios.

Nas preferências das interações entre orientadores e cursistas, a comunicação síncrona predominou sobre a assíncrona, ainda que ambas sejam empregadas em momentos alternados, de acordo com os depoimentos. A primeira surge como organizadora dos "momentos de contato" inicial (PEREIRA et al., 2007, p. 14), para estimular interações e gerar vínculos, mas servirá posteriormente para a efetiva orientação das pesquisas e da constituição dos produtos. Somente 2 orientadores relataram não empregar ferramentas síncronas de comunicação em suas tarefas.

As ferramentas de videoconferência [como Skype, Google Hangout, Google Meet, Zoom] são as preferidas para as interações síncronas e levam a preferência dos orientadores sobre o uso do telefone móvel ou de aplicativos de comunicação instantânea [Whatsapp, citado por apenas 1 orientador por seu uso sistemático], tendo sido consideradas mais úteis e menos informais e ligeiras que as outras ferramentas.

Este interesse pela videoconferência é o que permitiria transcender interações "frias" do texto escrito para alguma afetividade e possibilidade de empatia, o que fica claro no depoimento e na tomada de consciência de uma orientadora experimentada: 
Depois também temos as questões familiares. Como os nossos estudantes são pessoas que não são muitos jovens, acima dos 40 anos e têm as suas vidas familiares, às vezes é uma mãe que está doente ou o filho agora está faltando às aulas... Isso tudo aparece no Skype. Por escrito, as pessoas não vão falar muito sobre isso, mas no Skype comentam tudo. [...] Mas eu nunca tinha pensado nisso (E4).

Esse "Skype", como a videoconferência é genericamente chamada nas entrevistas, emularia aqueles encontros entre orientadores e cursistas que poderiam ocorrer informalmente em um café ou almoço, por exemplo, como modo de estreitar os vínculos e a confiança pessoais.

Posto isso, identificou-se que o princípio da adaptabilidade, outro dos primados extraídos da proposta da curricular da Universidade Aberta (PEREIRA et al., 2007) se faz presente nas interações descritas pelos entrevistados: disponibilizar vários modos e plataformas aos orientandos, para atender alunos com perfis de aprendizagem distintos ou de acordo com as restrições de acesso aos recursos tecnológicos - problemas com conectividade à internet ou equipamento de informática precário, por exemplo.

Quanto às interações entre os orientadores, os entrevistados apontaram baixa ou nenhuma ocorrência em suas experiências profissionais até o momento. Reforça-se, assim, o caráter solitário da atividade de orientação, sob o qual os envolvidos reservam-se em compartilhar suas angústias e dificuldades de percurso. Fomentar as interações, com trocas de experiências e recursos entre os professores orientadores seria desejável, ao constatarmos que pouco se avançou desde a observação de Machado (2000) de que:

Pouco se fala entre os orientadores sobre o tema da orientação, pouco se troca, pouco se escreve e consequentemente pouco se lê, enfim... trata-se de uma atividade que constitui o quotidiano dos professores de pós-graduação, mas que permanece "invisível", para a qual ainda temos poucas palavras (MACHADO, 2000, p. 147). 
As interações entre cursistas não foram substancialmente verificadas nas entrevistas. De modo semelhante, as interações com uma supervisão educacional on-line são praticamente irrelevantes no momento, pois no quadro institucional da maioria dos cursos a função ainda não está plenamente constituída, o que se apresenta como um desafio às pesquisas futuras e à organização das estruturas funcionais nas diferentes instituições de ensino. Somente metade dos entrevistados declarou ter alguma interlocução com a coordenação dos cursos em que atuam, o que — em nossa percepção - é um desdobramento do baixo número de interações que ocorrem entre os professores orientadores.

Quanto aos modos e tempos verificados nestas interações, o uso da palavra escrita foi valorizado pela totalidade dos entrevistados. O depoimento de E4 é eloquente ao lembrar-nos que "no ambiente virtual as tecnologias facilitam, mas isso é muito baseado na escrita, é um processo de precisão" (E4). Em outro espectro, apenas dois orientadores [E2 e E3, ou 25\%] mencionaram o uso sistemático das redes sociais [Facebook, no caso] em suas atividades junto aos cursistas, o que demonstra que o prestígio das redes sociais ainda é restrito entre os entrevistados. Os aplicativos de mensagens instantâneas [Whatsapp, Telegram] também foram mencionados por apenas dois orientadores, e outros dois chegaram a comentar que evitam deliberadamente o uso destes recursos, por considerá-los efêmeros e informais para o contato acadêmico.

As interações por meio escrito são valorizadas pelos orientadores, não somente em razão dos produtos finais serem, de fato, textos escritos como artigos ou teses, mas pelo valor intrínseco que atribuem à produção textual:

Passando o momento inicial de reconhecimento, eu me baseio muito no texto, porque este é o material concreto que eles têm. Eu utilizo todos os recursos do Word para revisão [...] falo muito para eles não ficarem chateados porque a correção é minuciosa (E8). 
Por fim, o prazer intelectual e a valorização profissional experimentados nas atividades de orientação são fatores destacados pelos professores, que estimam a atividade dentre os muitos afazeres que normalmente possuem:

Eu gosto muito de orientar, gosto muito do tipo de interação horizontal que se estabelece com o orientando. É uma colaboração muito mais horizontal e que também te desafia. Porque todos nós já fomos orientados e sabemos o que que funciona e o que não funciona [...] e posso ir aprimorando algumas coisas, enfim, trabalhando e chegando às estratégias de trabalho mais colaborativas (E3).

A gratificação com a atividade de orientação de pesquisas e trabalhos finais adviria não somente da atividade-fim e do que ela representa para a pesquisa e a formação de professores e pesquisadores em nível superior, mas alia-se à perspectiva subjetiva de cumprimento de algo valioso aos participantes envolvidos. A possibilidade de pesquisadores experientes compartilharem sua experiência acadêmica e científica, constituindo o acúmulo de saberes por meio desta relação on-line posta com os pesquisadores em formação, certamente possui um apelo entre os professores que entrevistamos.

Estes apontamentos tratam-se de uma tentativa de reflexão e sistematização de um processo que, até o presente momento, possuiu um caráter predominantemente empírico, como apontado por Machado (2000). Espera-se, com isso, ultrapassar o quadro retratado pelo entrevistado 2: "Você orienta como foi orientado, depois vai aos poucos formando seu perfil... ou faz o contrário daquilo que não gostou”.

\section{Considerações finais}

A discussão sobre a orientação de trabalhos finais em cursos on-line demanda a apropriação de conhecimentos variados, relacionados aos processos pedagógicos específicos da modalidade, o trabalho colaborativo e a natureza inter e multidisciplinar destes. 
A atividade de orientação, corrente no meio acadêmico presencial e tradicionalmente estabelecida, foi sendo transposta para as recentes modalidades educacionais suportadas pelas novas ferramentas de informação e comunicação. No entanto, a discussão dos fundamentos pedagógicos e gestionários inerentes ainda carece de publicações, simpósios, cursos de formação continuada que promovam a circulação e debate dos múltiplos aspectos envolvidos.

Este recorte de uma investigação mais ampla sobre os fundamentos e práticas de orientação procurou estimular este debate, com desdobramentos possíveis na formação continuada dos professores, na elaboração de propostas de trabalho colaborativo - entre orientadores, gestores e os cursistas - e no desenho curricular dos cursos ofertados.

Necessidades foram postas neste percurso de orientação, como a identificação de um perfil comunicacional e de aprendizagem do cursista, o estabelecimento de uma rotina de interações síncronas entre professores e alunos; a constituição de um material de apoio e suporte aos orientandos; e a valorização da palavra escrita nos processos de orientação por meio dos fóruns e produções textuais parciais.

Outra lacuna identificada é a carência de formação continuada para a orientação de trabalhos finais, a ser preenchida por pesquisas e cursos específicos, um desafio para os formadores em nível de pós-graduação no Brasil e em Portugal. Examinar as interações possíveis ajudaria a obter pistas sobre os possíveis caminhos metodológicos, as ferramentas de comunicação mais ou menos úteis, os espaços e tempos de interação mais ajustados às necessidades dos alunos.

\section{Referências}

ALBUQUERQUE, D. I. P. et al. Elementos Norteadores para orientação na educação a distância. In: Anais... Presidente Prudente: FCT/CPIDES, 2015. p. 720-729. 
ALMEIDA, C. A. Aspetos da interação online numa unidade curricular de $2^{\circ}$ ciclo da Universidade Aberta: desenho de atividades de estratégias discursivas de dinamização das aprendizagens. In: AIRES, L. et al. Educação a distância e diversidade no ensino superior. Lisboa: Universidade Aberta, 2014. p. 81-90.

BARDIN, L. Análise de conteúdo. Lisboa: Edições 70, 1977.

CABRAL, P. M. B. A. Interação em diferentes cenários pedagógicos no ensino superior online. 256f. Tese (Doutoramento em Educação na área de especialização de eLearning e Educação a Distância) — Universidade Aberta, Lisboa, 2015.

CHASSOT, A. I. Orientação virtual: uma nova realidade. In: BIANCHETTI, L.; MACHADO, A. M. N. (orgs). A bússola do escrever: desafios e estratégias na orientação e escrita de teses e dissertações. 2. ed. Florianópolis: Editora da UFSC; São Paulo: Cortez, 2006. p. 89-108.

DIAS, P. et al. eLearning no ensino superior português: um estudo sobre conceções de líderes académicos e pedagógicos. In: DIAS, P; MOREIRA, D.; QUINTASMENDES, A.(coord.). Práticas e cenários de inovação em educação online. Lisboa: Universidade Aberta, 2016. p. 12-45.

FERRETTI, C. J. Acompanhando o processo de escrever de mestrandos e doutorandos: um depoimento. In: BIANCHETTI, L. Trama e texto: leitura crítica, escrita criativa. v.2. São Paulo: Plexus; Passo Fundo: EDIUPF, 1997. p. 149-156.

GIL, A. C. Como elaborar projetos de pesquisa. São Paulo: Atlas, 2002.

MACHADO, A.M. N. A bússola do escrever: sobre a função da orientação de teses e dissertações. Revista FAMECOS, Porto Alegre, n. 13, p.140-147, dez. 2000.

MARQUES, M. O. A orientação da pesquisa nos programas de pós-graduação. In: BIANCHETTI, L.; MACHADO, A. M. N. (orgs). A bússola do escrever: desafios e estratégias na orientação e escrita de teses e dissertações. 2. ed. Florianópolis: Editora da UFSC; São Paulo: Cortez, 2006. p. 227-234.

MILL, D. et al. O desafio de uma interação de qualidade na educação a distância: o tutor e sua importância nesse processo. Cadernos da Pedagogia, v. 2, n. 4, p. 112-127, 2008. 
MOORE, M. Three types of interaction. American Journal of Distance Education, v. 3, n. 2, p. 01-06, 1989.

PEREIRA, A. et al. Modelo pedagógico virtual da Universidade Aberta. Lisboa: Universidade Aberta, 2007.

PRIMO, A. O aspecto relacional das interações na Web 2.0. E-Compós, v. 9, p. 0121, Brasília, 2007.

REDECKER, C. European framework for the digital competence of educators: DigCompEdu. Luxembourg: Publications Office of the European Union, 2017.

SAVIANI, D. Pós-graduação em educação no Brasil: pensando o problema da orientação. In: BIANCHETTI, L.; MACHADO, A. M. N. (orgs). A bússola do escrever: desafios e estratégias na orientação e escrita de teses e dissertações. 2. ed. Florianópolis: Editora da UFSC; São Paulo: Cortez, 2006. p. 135-164.

SOUSA, S.; DIAS, P. Como cultivar interações confiáveis. Um esforço para a sustentabilidade da educação aberta e em rede. In: DIAS, P.; MOREIRA, D.; QUINTAS- MENDES, A. (coord.) Novos olhares para os cenários e práticas da educação digital. Educação a Distância e eLearning, n. 2. Lisboa: UAb. 2017. p. 10-43.

Recebido: 31/07/2018

Received: 07/31/2018

Recibido: 31/07/2018

Aprovado: 02/02/2019

Approved: 02/02/2019

Aprobado: 02/02/2019 